\title{
Study of Newly Diagnosed Hypertensive Patients
}

\author{
Dinkar Narayanbhai Goswami ${ }^{1}$, Kruti Rajvansh ${ }^{2}$, Chirayu Vijaykumar Vaidya ${ }^{3}$ \\ ${ }^{1}$ Associate Professor, Department of Medicine, GMERS Medical College, Gandhinagar, ${ }^{2}$ Consultant Physician, N.H.L. Medical \\ College and V.S. Hospital, Ahmedabad, ${ }^{3}$ Assistant Professor, Department of Medicine, GMERS Medical College, Himmatnagar, \\ India
}

Corresponding author: Dr. Chirayu V. Vaidya, Plot No. 1371/2, Sector-2/B, Gandhinagar, Pin -382002, India

DOI: http://dx.doi.org/10.21276/ijcmsr.2019.4.2.24

How to cite this article: Dinkar Narayanbhai Goswami, Kruti Rajvansh, Chirayu Vijaykumar Vaidya Study of newly diagnosed hypertensive patients. International Journal of Contemporary Medicine Surgery and Radiology. 2019;4(2):B107-B110.

\section{A B S T R A C T}

Introduction: In modern era due to stressful lifestyle patients with hypertension are in rising trend. If undiagnosed and untreated it will lead to end organ damage. This study was aimed to study various clinical parameters, laboratory parameters, electrocardiographic and echocardiographic findings in newly diagnosed hypertensive patients.

Material and methods: This is a Cross-Sectional Study of all pts with first time detected hypertension in indoor and outdoor dept from August 2014 to July 2016in medical department of a tertiary care hospital. All the patients were interviewed as per the prior designed sheet.

Results: Maximum pts of hypertension were amongst elderly (61-70 years) and least in young(18-30 age) with male preponderance. Risk factors were tobacco consumption and alcohol, dyslipidemia, positive history of CVD and obesity were seen in 44\%, 44\%, 30\% and $16 \%$ respectively. Commonest symptoms were Headache (25\%) and chest pain (21\%). Commonest findings in ECG were LV Strain (42\%) and LVH (30\%). The most common observation in 2D ECHO was concentric LVH (64\%). Majority (41\%) were having essential hypertension.

Conclusion: Causation of hypertension is depended on multiple factors like age, sex, sedentary life style, obesity, addiction and hormonal changes. Addressing these factors help in knowing and dealing with it in a better manner.

Keywords: Hypertension, Headache, LV strain, Dyslipidemia

\section{INTRODUCTION}

Hypertension is a amongst the major health problems because of risks associated with it like cerbrovascular accidents, nephropathy and retinopathy. ${ }^{1}$ It is the major risk factor for cardiovascular diseases which kill about 12 million annually worldwide. ${ }^{2}$ According to American Heart Association, the estimated prevalence of hypertension was $73,600,000 .^{3}$ As per one data, $20.6 \%$ of Indian men and $20.9 \%$ of Indian women were suffering from HTN in 2005. ${ }^{4}$ Uncontrolled hypertension is a serious public health issue, in respect to morbidity, mortality and high cost in elderly. ${ }^{5}$

Hypertension is defined as blood pressure of systolic over 140 and diastolic over $90 \mathrm{~mm} \mathrm{Hg}$. This elevation makes the heart work harder against increased peripheral arterial resistance. ${ }^{6,7}$ It is known as silent killer because pts are not aware of symptoms until damage to organs as the brain and kidneys. ${ }^{8}$ Various risk factors like age, sex, race, sedentary life style, obesity, tobacco consumption and hormonal changes. ${ }^{9}$ Addressing these risk factors may help in reducing preventable risk factors such as weight, excess salt intake, cigarette smoking and alcohol use. ${ }^{10}$

The aim of hypertension treatment is to prevent complications by achieving and maintaining the blood pressure at 140/90 $\mathrm{mm} \mathrm{Hg}$ or lower. ${ }^{11,12}$ Pharmacological and life style changes are cornerstone in the treatment of this disease. ${ }^{12}$ Pts need to be taught about modifiable risk factors and lifestyle changes. ${ }^{13}$

This study's aim was to assess clinical parameters, laboratory parameters, electrocardiographic and echocardiographic findings in newly diagnosed hypertensive patients.

\section{MATERIAL AND METHODS}

The present study was undertaken in medical department of N.H.L. medical college and V.S. hospital.It was Hospital Based Descriptive Cross-Sectional Study including All adults presented with first time hypertension as indoor as well as outdoor patients from August 2014 to July 2016.

After due permission of institutional ethical committee all the patients were interviewed with proper interview sheet after informed consent of pts, which was designed especially for this study.

\section{Inclusion Criteria}

All adult patients of age greater than 18 years after informed consent with First time diagnosed hypertension according to JNC 8 guideline.(Systolic blood pressure >140; Diastolic Blood Pressure >90)

\section{Exclusion Criteria}

1. Pregnant pts

2. Patients with co morbid conditions like diabetes mellitus, 
ischemic heart disease and cerebrovascular accidents

3. Patients on any medications or on hormonal therapy which may alter blood pressure readings

4. Patients needing ICU management.

\section{Investigations}

- Blood pressure was measured with a mercury sphygmomanometer. Two measurements with 15 minutes apart on each arm with the patient sitting and supine. JNC 8 guideline ${ }^{14}$ was followed to diagnose hypertension(hypertensive individuals: systolic pressure $>140 \mathrm{mmHg}$ or diastolic pressure $>90 \mathrm{mmHg}$ ).

- $\quad$ Fasting lipid profile was done in lab.Bllod sugar was

\begin{tabular}{|l|c|c|}
\hline Age in years & No of patients & \% of patients \\
\hline $18-30$ & 1 & $1 \%$ \\
\hline $31-40$ & 8 & $8 \%$ \\
\hline $41-50$ & 20 & $20 \%$ \\
\hline $51-60$ & 21 & $21 \%$ \\
\hline $61-70$ & 37 & $37 \%$ \\
\hline $71-80$ & 13 & $13 \%$ \\
\hline Total & 100 & $100 \%$ \\
\hline \multicolumn{2}{|c|}{ Table-1: Age wise distribution } \\
\hline
\end{tabular}

\begin{tabular}{|l|c|c|}
\hline Complaints & No. of patients & \% of patients \\
\hline Headache & 25 & $25 \%$ \\
\hline Chest Pain & 21 & $21 \%$ \\
\hline Nausea & 15 & $15 \%$ \\
\hline Giddiness & 15 & $15 \%$ \\
\hline Limb Weakness & 14 & $14 \%$ \\
\hline Gabharaman & 12 & $12 \%$ \\
\hline Perspiration & 11 & $11 \%$ \\
\hline Vomiting & 10 & $10 \%$ \\
\hline Slurring of Speech & 7 & $7 \%$ \\
\hline Dyspnea & 6 & $6 \%$ \\
\hline Vision Disturbance & 4 & $4 \%$ \\
\hline Epistaxis & 2 & $2 \%$ \\
\hline Altered Sensorium & 2 & $2 \%$ \\
\hline \multicolumn{2}{|c|}{ Table-2: Complaints wise distribution } \\
\hline
\end{tabular}

\begin{tabular}{|l|c|}
\hline Risk factors & No. of patients \\
\hline Addiction & $44(44 \%)$ \\
\hline Dyslipidemia & $44(44 \%)$ \\
\hline Positive Family History & $30(30 \%)$ \\
\hline Obesity/Overweight & $44(44 \%)$ \\
\hline More than 1 Risk factor & $9(9 \%)$ \\
\hline \multicolumn{2}{|c|}{ Table-3: Risk factors } \\
\hline
\end{tabular}

\begin{tabular}{|c|c|c|c|c|c|}
\hline ECG findings & No of patients & $\%$ of patients & ECHO finding & No of patients & $\%$ of patients \\
\hline LV Strain & 42 & $42 \%$ & Concentric LVH & 64 & $64 \%$ \\
\hline LVH Alone & 30 & $30 \%$ & RWMA & 24 & $24 \%$ \\
\hline ST- T Changes & 14 & $14 \%$ & No Significant abnormality & 12 & $12 \%$ \\
\hline T wave changes & 9 & $9 \%$ & \multirow[t]{3}{*}{ Total } & \multirow[t]{3}{*}{100} & \multirow[t]{3}{*}{$100 \%$} \\
\hline Normal & 5 & $5 \%$ & & & \\
\hline Total & 100 & $100 \%$ & & & \\
\hline
\end{tabular}

done and the diagnosis of diabetes was made according to the definition of the American Diabetes Society. ${ }^{15}$

- The BMI was obtained by dividing the weight (in $\mathrm{kg}$ ) by the square of the height (in $\mathrm{m}^{2}$ ). According to the definitions of the World Health Organization for obesity, the patients were classified as follows: normal weight $\left(B M I<25 \mathrm{~kg} / \mathrm{m}^{2}\right)$, overweight $\left(\right.$ BMI $25 \mathrm{~kg} / \mathrm{m}^{2}$ and $\left.<30 \mathrm{~kg} / \mathrm{m}^{2}\right)$ and obese $\left(\mathrm{BMI}>30 \mathrm{~kg} / \mathrm{m}^{2}\right)$.

- Electrocardiographically, LVH was diagnosed on the basis of increased voltage (LVH alone) and repolarization abnormality (LVH and Strain). Sokolow-Lyon criteria were used to diagnose LVH electrocardiographically. Measurement of left ventricular wall thickness e.g. intenventricular septal thickness (IVST) and left ventricular posterior wall thickness in diastole (PWTd) by Mmode echocardiography was done. LVH was considered to be present if the IVST and PWTd are above their normal limits (> $12 \mathrm{~mm}$ in diastole).

\section{STATISTICAL ANALYSIS}

Observations were analyzed using the SPSS software version 21.

\section{RESULTS}

In our study there were 100 adults patients were there. Results were as follows.

Table-I shows that highest number of (37\%) patients were in 61-70 age group and lowest (1\%) in 18-30 age group. Patient of 30 yrs was youngest and 79 yrs was the eldest. In our study 62 (62\%) patients were Male. Remaining 38 (38\%) were Female. In present study as per (Table-II), The most common symptom was headache 25 (25\%) patients followed by Chest in $21(21 \%)$. The least common symptoms were epistaxis and altered sensorium seen in 2 (2\%) each. In our study 56 (56\%) patients had normal BMI, 28 (28\%) were overweight and 16 (16\%) were obese. Table III shows, risk factors like addiction in form tobacco consumption in any form and alcohol were present in 44 (44\%) patients. Family history of Hypertension, Cardiovascular disease and Diabetes mellitus were present in $30(30 \%)$ patients, Dyslipidemia was present in 44 (44\%) patients. $44 \%$ patients had high BMI (overweight/obese). It was observed that $9(9 \%)$ of patients had more than one risk factor. Overall Mean Blood Pressure is 175/100. In our study, retinopathy was present in $14(14 \%)$ patients at the time of diagnosis of hypertension.

It has also observed that $27(27 \%)$ patients had impaired glucose tolerance, 11 (11\%) patients were diagnosed having diabetes mellitus. In our study, LV Strain was the most common finding seen in ECG (42\%). Other findings 
like LVH, ST-T changes, T wave changes and normal electrocardiogram were present in 30 (30\%); $14(14 \%)$; 9 (9\%) and $5(5 \%)$ patients respectively. In our study, 2DEchocardiography showed Concentric LVH in 64 (64\%) patients, RWMA in 24 (24\%) patients and No Significant abnormality in 21 (21\%) patients. Maximum (41\%) were having accelerated hypertension. Whereas from remaining patients, (27\%) patients were found to have IGT, (24\%) presented with Cardiovascular disease; (20\%) presented with CV stroke; (5\%) with renal pathology. There was no mortality in this study. All the patients clinically improved after treatment.

\section{DISCUSSION}

In our study maximum were elderly (61-70 years) In study done by Reis et al ${ }^{16}$ highest incidence was present in 51-60 age group. One of the explanation tot this finding is increased risk of developing hypertension the sixth decade of life is approximately $90 \% .{ }^{13}$ Majority (62\% males vs. 38\% females) were Males. Study done by C. Cuspidi et $\mathrm{al}^{17}$, similar results were observed (52.4\% vs $47.6 \%)$. Sex difference in incidence is due to biological factors like sex hormones, chromosomal differences, and other biological sex differences that are protective for females. Till menopausal age these difference is effective that sex difference will be non effective. Renin activity in male is more than female of same age. ${ }^{18}$ In study of Gus et $\mathrm{al},{ }^{19}$ headache was the most common symptom(33\%). Anxiety neurosis and sleep apnea depict possible correlation between headache and hypertension. ${ }^{20}$ In the study of Reis et $\mathrm{al}^{16},(17.4 \%)$ patients were obese which is comparable to this study. Some studies showed link between weight and hypertension. ${ }^{21}$

In risk factors addiction like tobacco/ bidi/ chikkani/ alcohol was most common followed by Family history of HTN, CVD, DM, Dyslipidemia and high BMI (overweight/ obese), in study by Reis et $\mathrm{al}^{16},(30.4 \%)$ patients were smokers, $(17.4 \%)$ patients were obese $(\mathrm{p}=0.0006),(35.4 \%)$ patients were having dyslipidemia. In the study of Seham et $\mathrm{al}^{22}$, (75\%) patients had positive family history of cardiovascular diseases.Chemical compounds in tobacco mixtures are responsible for development of hypertension. ${ }^{23}$

Association of alcohol and blood pressure is also explained by few studies. ${ }^{24}$ Family history of cardiovascular disease also contribute to development of hypertension due to sharing of genes, behaviors, lifestyles and environments in them. Dyslipidemia causes endothelial damage leading to increased blood pressure. ${ }^{25}$ There is direct association between obesity and hypertension. ${ }^{21}$ Average Blood Pressure was 175/100, consistent with study by Cuspidi et $\mathrm{al}^{17}$ where it was was 168/103 (SBP/DBP).

In our study, retinopathy was present in (14\%) patients at the time of diagnosis of hypertension. In a study done by Meenakshisundaram $\mathrm{R},{ }^{26}$ retinopathy was seen in $69 \%$ patients in newly detected hypertensive patients. Increased blood pressure will damage retinal vessels leading to bleeding and complete blindness.

In our study majority pts were having dyslipidemia which was compatible with study of Reis et $\mathrm{al}^{16}$, (35.4\%) patients were having dyslipidemia.
In the present study, LV Strain was the most common finding seen in ECG (42\%). These results were comparable to a study done by Razzak et al. ${ }^{27} \mathrm{LVH}$ is due to increased pressure oveload. ${ }^{28}$

In the present study, 2D- Echocardiography finding shows Concentric LVH in (64\%) patients which was consistent with study by Razzak et $\mathrm{al}^{27}$ Concentric $\mathrm{LVH}$ was seen in (66\%) patients.

Maximum (41\%) had accelerated hypertension, (27\%) patients were found to have impaired glucose tolerance and (24\%) presented with CVD. As per Ayodele OE et al, ${ }^{29}$ (14.9\%) had associated diabetes and $19.7 \%$ had associated cardiovascular disease. It is studied that hypertension rarely presents in isolation, and it is usually associated with CVD comorbidities, such as CHD, stroke, heart failure, chronic kidney disease, diabetes mellitus, the metabolic syndrome, and dyslipidemia. ${ }^{30}$

\section{CONCLUSION}

Elderly (61-70 years age group) had high prevalence of hypertension with higher incidence in male (62\%). Risk factors like tobacco/ biddi/ chhikani/ alcohol, dyslipidemia, positive history of CVD were highest with equal incidence of (44\%). Commonest symptom was Headache (25\%). Among all newly diagnosed hypertensive patients, maximum had dyslipidemia (44\%). In ECG commonest finding was LV Strain (42\%). Maximum pts (41\%) had essential hypertension. Many pts were having co morbidities like impaired glucose tolerance, CVD, Stroke, DM and (5\%) had kidney pathology at the time of diagnosis. There was no mortality in this study.

\section{REFERENCES:}

1. Global status report on noncommunicable diseases. Geneva: World Health Organization; 2014

2. Chavez M.L., Knowledge and Practices on Hypertension of Adults: An Interventional Study by Trained Volunteer Health Workers in Barangay Militar, Tukuran, Zamboanga Del Sur, The Faculty of the Zamboanga Medical School Foundation, I.N.C. Zamboanga City, Doctral Degree of Medicine, 2000, $\mathrm{p}$ $3,20$.

3. Mary Beth M.R., Low S.Y. and Chung P.Y., Study to Assess the Knowledge on Self-Blood Pressure Monitoring among Hypertensive Patients in Selected Wards of Hospital Lam WahEe, Malaysia, School of Health Sciences, International Medical University, Kuala Lumpur, Malaysia, Ie JSME, 2012;6(2): 43-45.

4. Anchala R, Kannuri NK, Pant H, Khan H, Franco OH, Di Angelantonio E, Prabhakaran D. Hypertension in India: a systematic review and meta-analysis of prevalence, awareness, and control of hypertension. Journal of hypertension. 2014;32(6):1170-7.

5. Ogedegbe G., Fernandez S., Fournier L., Silver S.A., Kong J., Gallagher S., de la Calle F, Plumhoff J., SethiS.,Choudhury E. and Teresi J.A., The Counseling Older Adults to Control Hypertension $(\mathrm{COACH})$ trial: Designand methodology of a Group-Based Lifestyle Intervention for Hypertensive Minority Older Adults. Contemporary Clinical Trials, 2013; 35(2):70-79.

6. Leconte M. M. and Ismael V., Teaching Plan for High 
Blood Pressure Management, College of Technology, New York City, 2012, p 126.

7. Allender J., Rector C. and Warner K., Community Health Nursing: Promoting and Protecting the Public's Health, 7th ed., New York: Lippincott, Williams \& Wilkins, 2010; pp 300.

8. Cunha J. P. and Marks J W. High blood pressure (hypertension). Available: htt// www.medicinenet.com / high_blood_pressure/article.htm. Accessed 27 February 2011.

9. Thomas J.W. and Ramachandran S.V., Epidemiology of Uncontrolled Hypertension in the United States, Circulation journal, 2005; 112(3):1651-1662.

10. Davidson S., Principles and Practice of Medicine. Seventeenth Edition. Churchill Livingstone Com. 2002:pp.266.

11. Lambert E.V., Steyn K., Stender S., Everage N., Fourie J.M. and Hill M., Cross-Cultural Validation of the Hill-Bone Compliance to High Blood Pressure Therapy Scale in a South African, Primary Health Care Setting. Ethnicity Dis., 2006;(16):286-91.

12. Mersal F. A. and Mersal N.A., Effect of Evidence Based Lifestyle Guidelines on Self Efficacy of Patients with Hypertension, International J. of Current Microbiology and Applied Science, 2015; 4(3): 244-263.

13. Whelton PK. Epidemiology of Hypertension. Lancet. 1994;344(4):101-106.

14. James PA, Oparil S, Carter BL, Cushman WC, Dennison-Himmelfarb C, Handler J, Lackland DT, LeFevre ML, MacKenzie TD, Ogedegbe O, Smith SC. 2014 evidence-based guideline for the management of high blood pressure in adults: report from the panel members appointed to the Eighth Joint National Committee (JNC 8). Jama. 2014;311(5):507-20.

15. Expert Committee on The Diagnosis and Classification of Diabetes Mellitus. Report of the The Expert Committee on the Diagnosis and Classification of Diabetes Mellitus. Diabetes Care 1997; 20(6): 1183-97.

16. Rafael S. Reis, Isabela J. Benseñor, Paulo A. Lotufo, Laboratory Assessment of the Hypertensive Individual. Value of the Main Guidelines for High Blood Pressure Arq Bras Cardiol volume 73, (2), 1999.

17. C Cuspidi, I Michev, L Lonati et al. Compliance to hypertension guidelines in clinical practice: a multicentre pilot study in Italy Journal of Human Hypertension 2002;16(2):699-703.

18. Schunkert H, Danser AHJ, Hense H-W, Derkx FHM, Kurzinger S, Riegger GAJ. Effects of estrogen replacement therapy on the reninangiotensin system in post-menopausal women. Circulation.1997;95(6):39-45.

19. Gus M, Fuchs FD, Pimentel M, Rosa D, Melo AG, Moreira LB. Behavior of ambulatory blood pressure surrounding episodes of headache in mildly hypertensive patients. Arch Intern Med 2001; 161(2):252-255.

20. Stewart, I. M. G.: Headache and Hypertension, Lancet 1953; 264(4):1261.

21. Hsueh WA, Buchanan TA. Obesity and hypertension. Endocr Metab Clin North Am 1994; 23(3): 405 - 427.

22. Seham A. Abd El-Hay, Samira E. El Mezayen Knowledge and Perceptions Related to Hypertension,
Lifestyle Behavior Modifications and Challenges That Facing Hypertensive Patients, 2001;4(6):15-26.

23. J. C. Byrd. Environmental tobacco smoke: medical and legal issues.Medical Clinics of North America 1992;76(2):377-398.

24. Beilin LJ. Alcohol, hypertension and cardiovascular disease. J Hypertens. 1995;13(3):939-942.

25. Oparil S, Zamen MA, Calhoun DA, Pathogenesis of hypertension, Ann Intern Med, 2003; 139(5); 761 -776.

26. Meenakshi sundaram R, Babuvinish D, Grootveld M, Rajendiran C, Thirumalai kolundu subramanian P. Status of End Organs in Newly Detected Rural Essential Hypertensives: A Study from Southern India. Clinical and Experimental Hypertension. 2012;34(3):201-8.

27. M Razzak Mia, ARM Saifuddin Ekram, M Azizul Haque, Raisuddin A Comparative Study of Electrocardiographic and Echocardiographic Evidence of Left ventricular Hypertrophy TAJ 2007; 20(1): 2427.

28. Lee JH, Park JH. Role of echocardiography in clinical hypertension. Clinical hypertension. 2015;21(1):1.

29. Ayodele OE, Alebiosu CO, Akinwusi PO, Akinsola A, Mejiuni A. Target organ damage and associated clinical conditions in newly diagnosed hypertensives attending a tertiary health facility. Nigerian journal of clinical practice. 2007;10(4):319-25.

30. Wong ND, Lopez VA, L'Italien G, et al. Inadequate control of hypertension in US adults with cardiovascular disease comorbidities in 2003-2004. Arch Intern Med 2007; 167(3):2431-2436.

\section{Source of Support: Nil; Conflict of Interest: None}

Submitted: 19-04-2019; Accepted: 25-05-2019; Published online: 15-06-2019 